\title{
Do Caos ao Renascimento do Espaço Psíquico
}

\section{Maria Fernanda Alexandre ${ }^{1}$}

\begin{abstract}
Resumo
A autora faz uma elaboração psicanalítica a partir de uma investigação clínica de um caso de uma criança, onde destaca as diferentes consequências psíquicas ocorridas na sequência de separações e de perdas precoces. Mostra como o desmoronamento psíquico, que surge na sequência da ausência do objeto materno, provoca um encapsulamento narcísico, de difícil acesso, e que funciona como uma barreira que anula ou que evita as relações de proximidade. Destaca e elabora os diferentes movimentos do processo analítico, que vão do caos, à construção de um continente sonoro que envolve a dupla analítica e ao nascimento das primeiras palavras que serviam para representar a depressão primária.
\end{abstract}

Palavras-Chave

Caos psíquico, Espaço psíquico, Depressão primária, Transformações psíquicas

«Antes do mar e das terras e do céu, que tudo cobre, um só era o aspecto da natureza no orbe inteiro:

Caos lhe chamaram. Era uma massa informe e confusa, nada a não ser um peso inerte, nela amontoando-se as sementes discordantes de coisas desconexas $[\ldots] . »$

«Nada conservava a sua forma cada coisa opunha-se à outra, pois num mesmo corpo o frio guerreava o quente, o húmido lutava com o seco, o mole com o duro, o peso com a ausência de peso.» Ovídio, Metamorfoses, Livro 1, 1 e 15

1 Psicóloga Clínica e da Saúde, Psicoterapeuta e Psicanalista. Psicanalista de Crianças, Adolescentes e Adultos e Membro Titular, com funções didáticas, da Sociedade Portuguesa de Psicanalise (SPP) e da Associação Internacional de Psicanalistas (IPA). E-mail: mfgalexandre1908@gmail.com

(c) do Autor 2021. Publicado online em https://rppsicanalise.org, sob a Licença Creative Commons Atribuição-NãoComercial 4.o Internacional. Seguindo a exigência da preservação do anonimato dos pacientes e da confidencialidade, o material clínico é apresentado com alteração da identidade do paciente e de dados clínicos.

\section{INTRODUÇÃO}

A elaboração deste trabalho assenta numa investigação clínica realizada ao longo de muitos anos com crianças que viveram experiências traumáticas precoces, de privações e de ruturas, com consequências dolorosas para o seu desenvolvimento psíquico. Estas experiências internas, vividas muito precocemente, põem em evidência mecanismos de defesa muito primitivos, que se organizam de forma que possam evitar as angústias precoces que derivam dos sentimentos de aniquilação, de perda e de morte. No seguimento destes estados do funcionamento da mente, podem surgir um conjunto de defesas, com características psicóticas, depressivas ou persecutórias, que têm a função de criar uma barreira defensiva contra a dor que é sentida, mas que não pode ser representada.

Os trabalhos de investigação e de observação de bebés trouxeram um contributo valioso para a 
compreensão desses estados primitivos da mente, assim como para a perceção «da emergência das primeiras representações mentais do bebé, que irão constituir a base da sua organização psíquica futura», como sublinha M. J. Gonçalves (2019, p. 62). Na sequência deste desabrochar psíquico do bebé, surge simultaneamente, como salienta esta autora, a capacidade de se fazer entender, transmitindo para o exterior, através desses sinais, os seus estados e as suas necessidades, mostrando, desta forma, as suas «capacidades de estabelecer ligações entre experiências sensoriais isoladas e separadas e permitir ao bebé ter a experiência da emergência» (idem, p. 63.). Mas, como a clínica e a literatura analítica nos mostram, estes estados da mente do desenvolvimento do bebé podem sofrer uma reversão - tal como o caso que apresentaremos - , devido a experiências psíquicas precoces de perda, de separação ou de rutura, que surgem na sequência de um desmoronamento psíquico vivido na relação precoce.

Nestas circunstâncias, como salienta Winnicott (1974), podem surgir, na fase de dependência do eu em relação ao ego auxiliar da mãe, um conjunto de defesas que se estruturam de forma que evitem um possível desmoronamento psíquico que a separação precoce provoca. Acrescenta, ainda, que o congelamento que se opera na parte primitiva da mente destas crianças seria uma defesa contra o colapso interno experimentado precocemente pela separação. Estamos em sintonia com este autor quando salienta que as defesas podem configurar-se como um baluarte autístico que pretende, por um lado, defensivamente, mostrar a sua omnipotência e invulnerabilidade, mas, na realidade, esta carapaça defensiva serve para esconder os sentimentos decorrentes de sensações de colapso interno que os sentimentos de abandono precoce podem desencadear.

Nestas crianças, que viveram separações muito precoces, como sublinha Mahler (1958), podem surgir dificuldades na consciência da sua própria identidade, e, defensivamente, constroem desde bebés reações de evitamento de forma que tomem a consciência traumática da separação física da mãe. Perante estas situações de perda vividas muito precocemente, estes pacientes apresentam, nas relações de proximidade, um afeto de evitamento ou de distância (Stern, 1996.). Este autor acrescenta ainda que estas crianças adquirem precocemente a consciência da dor traumática da separação, que ocorre no estado «do self emergente» que se dá antes do seu próprio desenvolvimento.

Estes pacientes que, prematuramente, viveram experiências de separação catastrófica podem defender-se da dor da perda através de um encapsulamento autístico, como descreve F. Tustin (1973). Defesa essa que tem a função de imobilizar uma parte danificada da personalidade, que surgiu no momento do cataclismo convocado pela separação. Desta forma, estes pacientes apresentam-se, como a experiência clínica nos mostra, com um pensamento concreto, com falhas marcadas ao nível da simbolização - por isso, com dificuldades de falar, brincar ou pensar -, e frequentemente evitam o olhar e refugiam-se num funcionamento obsessivo que se pode transformar numa muralha de difícil acesso representada por um núcleo autístico.

Meltzer (1975), com um grupo de colegas, publicou uma monografia onde investiga estas crianças com o «espectro» do autismo, que surge na sequência de, muito precocemente, reconhecerem a depressão da sua mãe, que é vivida por eles como uma catástrofe interna, e, nesse sentido, por defesa, destroem os elos de dependência de forma que se afastem e não prejudiquem essas mães deprimidas e desamparadas. Assim, para evitar a dor da rutura e perda, retiram-se e escondem-se numa espécie de casulo impenetrável ou de difícil acesso.

Estas crianças, que viveram perdas precoces, podem organizar-se, muito prematuramente, como salienta Ogden (1994), de forma que se mantenham num funcionamento de fase «autista-contígua», que representa uma experiência pré-simbólica, dominada pela sensorialidade. Estas configurações psicológicas primitivas caracterizam-se, como o autor assinala, por impressões protossimbólicas, experiências que constituem vivências precoces de superfície e de fronteira. 
Não podemos deixar de associar estes estados precoces da mente ao pensamento teórico de Anzieu (1974), que construiu, a partir da sua experiência clínica, o conceito do «Eu pele» e a sua passagem para o Eu psíquico, que se configura, segundo este autor, como uma fronteira vivida entre o Eu psíquico e o Eu corporal, entre o Eu realidade e o Eu ideal. Desta forma, mostra-nos como, com certos pacientes, podem surgir flutuações dentro destas fronteiras, que habitualmente são acompanhadas de depressão, indiferenciação e confusão entre as experiências agradáveis e dolorosas.

A nossa experiência clínica está em sintonia com estes autores, que sublinham que as mudanças e perdas precoces têm efeitos nefastos para o desenvolvimento da criança, instalando-se, assim, um clima de catástrofe que é acompanhado por uma dor sem nome que não é representada, mas a que podemos ter acesso através da relação analítica. Para evitar este desmoronamento psíquico, que a ausência do objeto provoca, refugiam-se num encapsulamento narcísico, de difícil acesso, que tem a função de evitar a proximidade ou de ser uma forma de esquecer, anular ou destruir esses elos psíquicos dispersando-os no tempo e no espaço.

\section{A SEPARAÇÃO VIVIDA COMO UMA CATÁSTROFE PSÍQUICA}

Estas experiências psíquicas de perda e de separação, vividas precocemente por estas crianças, mostram-nos, ao longo da dinâmica da relação analítica, a intensidade da dor psíquica, que dificilmente pode ser representada. Desta forma, gostaríamos de partilhar e de discutir algumas questões teóricas e clínicas que se nos colocaram ao longo de uma dessas análises, que realizámos com uma criança de seis anos. Esta relação psicanalítica, que durou sete anos, três vezes por semana - mas neste texto abordaremos especificamente o primeiro ano de psicanálise - , trouxe-nos interrogações, assim como apreensões, que de algum modo foram inspiradoras, porque nos permitiram pensar e elaborar sobre a dor psí- quica desta criança, bem como a dos seus pais. Dor que era difícil de representar, mas na qual, através da nossa contratransferência, podíamos ter acesso a uma espécie de sombra enigmática assustadora que não tinha nome, mas que se escondia por detrás de uma carapaça obsessiva impenetrável.

A separação dos pais, numa idade precoce — tinha então a criança três anos —, seguida de uma depressão melancólica da mãe, constituíra o marco a partir do qual reconheceram que o filho passou a isolar-se, a não brincar, perdendo assim a pouca linguagem que tinha. Contratransferencialmente, ficámos perdidos e sem palavras perante o estado caótico desta família, e, particularmente, da mãe, que passou a primeira consulta a chorar e a procurar palavras para poder falar da sua grande tristeza e desalento. O pai, embora mais contido, ia seguindo as palavras da mulher, mas também fazia um esforço para segurar as lágrimas. Os pais pareciam estar perdidos e com dificuldades de poder representar os sentimentos dolorosos que o estado do filho desencadeava neles. A maior dificuldade dos pais era o facto de ele não falar e de ser muito difícil fazerem-se compreender.

Num primeiro contacto, contratransferencialmente, ficámos com a ideia de que eles colocaram, metaforicamente, o bebé nos nossos braços numa confiança excessiva e omnipotente. Assim, confrontámo-nos, contratransferencialmente, desde os primeiros momentos, com um pedido urgente de socorro por parte dos pais em relação ao sentimento de desmoronamento psíquico do filho. Como contactar e elaborar estes abismos desconhecidos e enigmáticos, que não podiam ser representados, mas que esta criança e esta família projetavam em nós?

Através do processo analítico desta criança, encontraremos possíveis explicações para estas interrogações. Neste trabalho, apresentaremos somente o material clínico, do primeiro ano, que foi organizado da seguinte forma: primeiro, falaremos do caos, da desordem, dos desligamentos, da confusão; de seguida, abordaremos a importância da analista, cujas palavras não eram percebidas, mas à qual se mostrava sensível, à 
envolvência da sonoridade que funcionava como um continente que o protegia; depois, abordaremos a importância das primeiras palavras, que se ancoravam de uma forma obsessiva para tentar tapar ou apagar aquilo que ele chamava «buraco», assim como o esforço físico para o esconder, mostrando querer evitar falar e contactar com a depressão primária.

\section{NO PRINCÍPIO ERA O GAOS}

O processo analítico iniciou-se sobre a sombra de um Caos que representava a desordem, a confusão, a cisão e a separação, e que, metaforicamente, se configurava como uma luta mortífera entre Eros - as forças da vida que representam uma energia integradora - e Thanatos - que ataca as ligações e destrói os vínculos. Cada um desses instintos, como salientava Freud (1932) na sua carta a Albert Einstein, é «tão indispensável quanto o seu oposto, e todos os fenómenos da vida derivam de sua atividade» (p. 251).

Assim, no princípio do processo analítico, confrontámo-nos com uma criança que não nos olhava, ou mantinha um olhar distante e sem expressão, que entrava e saía do gabinete de trabalho e que tentava abrir ou fechar as portas de outras salas do espaço onde trabalhávamos. Procuraria alguém ou alguma coisa que tinha perdido? Parecia-nos não distinguir o interior do exterior, o que era próximo e o que era longínquo, nem ter limites ou fronteiras (Alexandre, 2007). Assim, a dinâmica da relação com esta criança, que nos primeiros três meses aparentava ser um robô, que se deslocava na sala dando encontrões nos móveis, mantendo um olhar distante e sem expressão, configurava-se, como Salomon Resnik (1991) salientava, sob a forma de um tempo e de um espaço petrificado, congelado para se proteger da catástrofe que a perda e a separação dos objetos de amor desencadeiam.

Contratransferencialmente, sentimos, desde os primeiros momentos, que a criança descrita pelos pais parecia não ser aquela que estava ali connosco. Apercebemo-nos de que surgia, na dinâmica da relação, uma espécie de paradoxo que se situava entre a criança que nos fazia um apelo para ser ajudada e que nos incentivava a segui-la nas suas deambulações para fora da sala, mas, simultaneamente, aquela que nos fazia um apelo para continuar aconchegada na sombra de uma identificação à depressão materna. Como sair deste paradoxo que paralisava o campo analítico?

Agarrado à chave do carro do pai, que funcionava como um «objeto autístico» (Tustin, 1981, p. 119) que o defendia da confusão com o objeto interno, continuava a deambular entre o dentro e o fora do gabinete, num jogo de presença e ausência. Tínhamos a sensação, contratransferencialmente, de partilhar com esta criança sentimentos de impotência perante a ameaça permanente de desintegração, que aparecia, como salientava S. Grotstein (1999), de uma morte psíquica que surge «da depressão primária que funciona como um primeiro desorganizador da vida psíquica quando associado a um funcionamento deficitário [...] resultado da incapacidade da mente para ordenar a sua confusão e ou para manter e regenerar e as suas estruturas» (p. 66). Como salientava este autor, nestes casos podemos detetar a emergência do nada e do sem sentido resultado de uma desintegração do self a partir do interior. Nestas circunstâncias, ocorre, como defesa contra a catástrofe da perda, um encapsulamento autístico, caracterizado por um imobilismo da parte danificada da mente. Assim, nesta fase do processo analítico, a dinâmica da relação é envolvida por um sentimento de procurar palavras para interpretar e representar este estado mental de retirada narcísica, vivida por esta criança, que mostrava o seu desamparo e deceção em relação ao objeto primário. Como salientou O. Fialho (2019), é sempre através do afeto que o ser humano reage aos estímulos, quer sejam internos ou externos, e é desta forma que se torna possível organizar o caos psíquico, permitindo assim uma harmonia ao longo do desenvolvimento. Deste modo, a presença da analista, representada através da melodia das suas palavras, permitiu construir um continente sonoro, que o envolvia e o abrigava da ameaça do desconhecido. 


\section{O NASCER DE UM CONTINENTE SONORO}

Na relação terapêutica com estas crianças, que sofreram precocemente perdas catastróficas, a presença do analista, através da sonoridade das suas palavras, pode pôr em evidência a sua capacidade materna de compreensão psíquica perante as necessidades e angústias do bebé.

Nesta situação clínica, embora as palavras não fossem verdadeiramente percebidas, pareciam funcionar como um continente sonoro que o protegia e o punha a salvo do desconhecido que o envolvia. Nesta altura, deixara de sair da sala e mantinha-se durante todo o tempo na sessão, e abandonara as chaves do pai, que funcionavam como um objeto autístico que o protegia da dor da perda e da separação. Ao longo de algumas semanas, o seu interesse fixou-se num pedaço de plasticina que transformou numa bola, que amassava de forma obsessiva, até à exaustão, e a que se agarrava como se fosse, metaforicamente, o seio materno. Continuava a evitar olhar para a analista, mas parecia estar atento às suas palavras, das quais não percebia o significado, mas que o envolviam num manto de sonoridade que o continha. Através do seu rosto, enquanto moldava a plasticina, podíamos contactar com uma paleta de emoções que nos mostravam certas experiências mentais primordiais, como medos, raivas, exaltação, alegria e outras. Nestas circunstâncias, competia ao analista pensar e encontrar palavras para estes afetos que estavam a circular na dinâmica da relação, mas que a criança ainda não podia nomear. Com estas crianças, como sublinha S. Grotstein (1999), forma-se um território autístico que é marcado por um espaço geometricamente redondo, como esta bola de plasticina, de que dificilmente se desprendia e que, ao longo do processo analítico, insistentemente moldava e desmoldava numa cadência parecida a uma cantilena sem palavras, só de sons que não podiam ser representados. Sentíamos, contratransferencialmente, que esta criança nos fazia um velado apelo, que não podia representar, para acolhermos e contermos certos aspetos insuportáveis do eu, caracterizados por experiências sensoriais que não puderam ser processadas, nem re- presentadas, mas que eram projetadas no espaço interno da analista. Assim, como sublinha Grotstein (2009), quando o analista funciona como um contentor - «continente» - das experiências do analisando, este, inconscientemente, identifica-se projetivamente com a imagem do analista. Nestas circunstâncias, a capacidade de rêverie da analista, que é uma função materna, permite acolher e transformar as identificações projetivas da criança em formas de representação, que estão presentes no processo psicanalítico.

Mas a dinâmica da relação entre continente e conteúdo, que é um processo psíquico ativo, pode por vezes apresentar-se, na clínica, de diferentes formas. Particularmente nestes casos, a qualidade desta relação configura-se, numa primeira fase, como parasitária, isto é, continente e conteúdo destroem-se mutuamente, como certos autores chamaram a atenção.

Nestas circunstâncias, colocam-se com estes pacientes alguns problemas de técnica analítica, uma vez que, neste caso que estamos a descrever, a construção psíquica da função de continente surge como o resultado do trabalho da dupla analítica, que contribui para a transformação e desintoxicação dos aspetos doentes da mente por uma identificação com o analista, devolvendo assim de uma forma desintoxicada aquilo que nele foi colocado. Foi passados cinco meses que pela primeira vez se dirigiu à analista e disse as suas primeiras palavras: «olha o carro». Colocou o carro em cima do pedaço de plasticina e andou com ele de um lado para outro durante uma eternidade, mostrando uma carapaça obsessiva de difícil contacto.

Nesta fase, quando íamos buscá-lo à sala de espera, escondia-se atrás do pai para ser encontrado. Estes jogos repetiam-se ao longo de diversas sessões, como se quisesse ser encontrado num jogo de presença-ausência da relação terapêutica. Nesta altura, quando após uma sessão ia ao encontro do pai, disse-lhe: «ela fala, ela fala», como se começasse a organizar e a falar de um continente sonoro que o envolvia. A nossa experiência clínica vai no mesmo sentido de alguns autores, particularmente J. Bégoin (2005), que constata que a função continente pode ser res- 
tabelecida «através do investimento da criança pela analista, formando-se, assim, um envelope sonoro de palavras e significações» que permite «começar a explorar o interior dos conteúdos maternos passando de uma relação adesiva bidimensional para uma relação tridimensional» (p. 97-98).

\section{O BURACO NEGRO}

As palavras continuavam a ser parcas, mas a criança mantinha a sua atenção e curiosidade à volta da bola de plasticina, e era através dela, amassando e fragmentando, que comunicava com o analista e representava o seu interesse, por vezes com laivos maníacos, daquilo que se passava no seu mundo interno. A dor psíquica, que até então não podia ser nomeada nem representada, surgiu a partir de um buraco que ele fez na plasticina. Pela primeira vez, olhou-nos nos olhos e disse: «tu não sabes, isto é um buraco, é fundo, é fundo... é preto». Esta criança começava, pela primeira vez, a nomear e a exprimir o buraco e o vazio interno, resultado do colapso vivido, precocemente, perante a depressão materna.

O buraco negro, como a literatura analítica nos tem mostrado, é sempre uma experiência relacionada com o instinto de morte e compreende os aspetos mais arcaicos e rudimentares da posição depressiva. Particularmente nestes pacientes, como salienta J. Grotstein (1999), esta fase antecede a posição esquizoparanoide, e o buraco negro será uma experiência potencial. Assim, este autor interroga-se e coloca a hipótese de a posição depressiva, nestes casos, poder anteceder e ser subjacente à posição esquizoparanoide, que regula ou modela a primeira fase do desenvolvimento psíquico. Acrescenta ainda que os processos ligados à posição esquizoparanoide - clivagem, identificação projetiva, idealização, negação omnipotente - têm a função de organizar o caos que surge na sequência da depressão primária. Desta forma, como observámos anteriormente, nestas crianças o funcionamento autístico surge como uma proteção em relação à depressão que é representada por um buraco negro. A propósito destes casos, Tustin descreve, numa carta escrita a Grotstein (1999), que: «[...] a vivência do buraco negro é o resultado direto de um estado funcional indevido entre mãe e o bebé. Quando as consciências da separação dos seus corpos se impõem a um par tão fundido, é traumático. Fica em ambos um buraco negro. $\mathrm{O}$ aspeto importante é que isto não é sarado pelos cuidados do pai, porque a sua influência foi inevitavelmente coartada pela excessiva fusão entre a mãe e o bebé» (p. 69-70).

Podemos então pensar que esta carapaça autística funcionaria como uma proteção contra a depressão primária, representada pelo buraco negro. Estes autores sublinham que a ausência da normal consciência da separação dos seus corpos impede a experiência da presença de fundo da identificação primária.

Neste caso, como em muitos outros, é a identificação da criança com a depressão da mãe que pode provocar este quadro de retraimento autístico. A criança pode sentir que não tem espaço dentro desta mãe deprimida e ausente, e neste sentido refugia-se numa posição de retraimento narcísico, como se se escondesse numa carapaça impenetrável de difícil contacto, em que os afetos se configuram e podem ser representados através de buracos. Nestas crianças, como sublinha Meltzer et al. (1978), há um transtorno no decorrer do seu processo normal de integração psíquica, vivido como uma forma de desintegração, transformando, desta maneira, os dados sensoriais em fragmentos de forma que sobreviva e suporte o seu desenvolvimento adequado.

Assim, ao longo do processo analítico, esta criança brincou algumas semanas com os diversos «buracos» que via em todos sítios da sala: «olha um buraco...», e tentava cobri-los e escondê-los pedindo-nos, insistentemente, ajuda nesta tarefa. Continuava a encontrar pequenos buracos - na verdade, eram diminutas fissuras na mesa e no chão - que tentava, com esforço, tapar. Insistentemente, pedia a nossa ajuda e iniciava-se uma transferência de grande proximidade, onde tentávamos, simbolicamente, através de interpretações, dar um nome a esses espaços esburacados. Desta forma, através de um movimento de identificação projetiva com a função conti- 
nente do analista, poderia permitir-se começar a representar estes buracos - que simbolizavam a qualidade da depressão narcísica primária - e transformá-los em histórias que podiam ser contadas.

\section{DISCUSSÃO E CONCLUSÃO}

Nestes pacientes, que viveram perdas e separações muito precocemente, desenvolvem-se defesas, como a encapsulação autística, que servem para imobilizar a parte danificada da mente de forma que não possa pensar-se nas tragédias que ensombraram o seu desenvolvimento psíquico. Nestas circunstâncias, como Bégoin (2005) assinala, esta paralisação psíquica organiza-se na sequência da impossibilidade da elaboração «dos elementos que nasceram da depressão primária» (p. 84). Acrescenta ainda que as partes paralisadas e mortas do self se apresentam sob a forma de um poder de destruição potencial, que paralisa toda a sua vida psíquica.

Estes pacientes, para poderem sobreviver a este desmoronamento psíquico, que surge da identificação precoce com o objeto que é vivido como distante, sem vida, paralisado como se tivesse morto, retiram-se narcisicamente de forma que evitem elaborar a destrutividade que tal situação desencadeia. Estes aspetos psíquicos surgem naturalmente, como anteriormente assinálamos, como uma defesa contra o afeto doloroso de se sentirem sem espaço no interior de uma mãe que é sentida como distante, ausente e presa numa depressão narcísica. A este propósito, Grotstein (1999) salienta que a depressão primária seria «o primeiro desorganizador da vida psíquica quando associada a um funcionamento deficitário da presença da identificação primária, e que seria o principal gerador de significação predispondo a criança ao risco de uma incomum vulnerabilidade e ao surgimento dos aspetos passivos e ativos do instinto de morte» (p. 66). Acrescenta ainda que nestas crianças a consciência da separação dos seus corpos impede a experiência da presença de fundo da identificação primária, e, naturalmente, podem surgir diferen- tes configurações do narcisismo. Como tivemos oportunidade de sublinhar, a ausência do objeto deixa um vazio ou um buraco que é acompanhado de um sentimento de falta ou de perda. Desta forma, como sublinha Resnik (1994), «não é só o objeto que se perde, mas também a ligação do eu a ele» (p. 70) que se esfuma e deixa de ter significado. Assim, a perda desencadeia uma intensa dor mental a que só podemos ter acesso através de um reduto de defesas narcísicas (Alexandre, 2007). Neste sentido, estas defesas são caracterizadas pela negação e confusão, que representam, como Tustin (1981) destaca, dois tipos de defesas narcísicas que têm a função de evitar e distanciar-se das partes danificadas da mente, que a perda e a separação desencadearam, mas que o analista contacta através das identificações projetivas do paciente. Neste mesmo sentido, Meltzer (1967) também sublinhava a importância deste mecanismo de defesa contra a angústia de separação. Com estes pacientes, interrogamo-nos, como já tivemos oportunidade de o fazer (Alexandre, 2007), de que forma poderemos entrar em contacto com os aspetos mortos da mente que não puderam ser pensados pelo paciente. $\mathrm{O}$ analista, através da sua contratransferência, intui a sua presença na dinâmica do espaço terapêutico e tenta encontrar uma representação, através da sua capacidade de rêverie, para o irrepresentável que circula na relação.

Como sublinhava Pontalis (1978), estas experiências internas abortadas de perdas e separações são desencadeadoras de uma dor que não pode ser representada, mas que se oculta num «eu-corporal». Tal como constatámos com esta criança, que seguimos em psicanálise, é o corpo que fala através de uma excitação entre o deambular sem sentido, entre o dentro e o fora do nosso espaço de trabalho. A dor, no caso que apresentamos, pode ter origem na deceção sofrida precocemente na sequência «da mudança do objeto que obriga o eu a uma renovação correspondente» (Green, 2007, p. 166), e que, nestas circunstâncias, foi a depressão materna vivida após separação conjugal. Como salientava este mesmo autor, o eu enquista-se no objeto, aprisionando-o de forma que possa manter com ele 
uma unidade inseparável para o controlar. Deste modo, a dor emerge na sequência desta luta para se libertar deste objeto que o aprisiona, mas que ao mesmo tempo o dececiona. Assim, a dor psíquica é envolvida num movimento paradoxal que se caracteriza, como assinala Green, por um lado, pelo controlo do objeto, identificando-se a ele, mas, por outro, pelo investimento negativo no buraco que simboliza a perda do objeto. O autor acrescenta ainda que o objeto da análise não deve centrar-se nem no paciente nem no analista, mas no espaço potencial, ou seja, no campo da relação analítica.

Como tivemos oportunidade de mencionar num outro trabalho (Alexandre, 2007), estas regressões narcísicas permitem restabelecer a situação primária de unicidade (Tustin, 1981) com a mãe, que precocemente se tinha retirado devido a uma profunda depressão. Assim, as suas aparentes brincadeiras à volta de chaves e carros não tinham uma função simbólica, mas serviam para «evitar tomar consciência da separação corporal» (Tustin, 1981, p. 127) com a analista. Estes objetos transformavam-se pouco a pouco num prolongamento do corpo da analista, de quem não se queria separar. Com a evolução do processo analítico, assistimos à passagem de uma simbolização do primeiro para o segundo grau. Nesta situação, como salienta Bégoin (1993), a função continente é restabelecida «a partir do investimento da criança pelo analista» (p. 97), que através do processo psicanalítico constrói «um envelope sonoro de palavras e significações, de maneira a poder começar a explorar o interior dos conteúdos maternos passando, assim, de uma relação adesiva bidimensional para uma relação tridimensional» (p. 98). Nestas circunstâncias, o processo psicanalítico pode contribuir e facilitar - como aconteceu com esta criança a passagem das identificações narcísicas para as identificações introjetivas, contribuindo para a transformação da dor, que não podia ser pensada, num sofrimento psíquico que pode ser representado e elaborado.

\section{BIBLIOGRAFIA}

Alexandre, M. F. (2007). Mudanças Psíquicas no Processo Terapêtico. O papel do Narcisismo. Fenda.

Anzieu, D. (1974). Le Moi Peau. Nouvelle Revue de Psychanalyse, 9, 195-208.

Bégoin, J. (2005). Depressão e destrutividade na vida psíquica da criança. Do Traumatismo do Nascimento à Emoção Estética - Conferências Psicanalíticas em Lisboa. Fenda.

Fialho, O. (2019). Desenho Infantil: Espelho do Mundo Interno da Criança. Colibri.

Freud, S. (1976). Porque a Guerra?. Em Edição Standard Brasileira das Obras Psicológicas Completas de Sigmund Freud, XXII. Imago, 241-259. (Obra original publicada em 1932.)

Gonçalves, M. J. (2019). Origem da vida psíquica, nascimento psíquico e originário. Revista Portuguesa de Psicanálise, 39 (2), 62-68.

Green, A. (2007). Narcisisme de Vie, Narcisisme de Mort. Éditions de Minuit.

Grotstein, J.S. (2009). “...But at the Same Time and on Another Level..." Clinical Applications in the Keinian/Bionian Mode. Karnac Books.

Grotstein, J. S. (1999). O buraco Negro. Climepsi.

Mahler, M. (1958). Autism and Symbiosis: two extreme disturbances of identity. The International Journal of Psychoanalysis, 39, 77-83.

Meltzer et al. (1978). The Kleinien Development. The Roland Harris Educational Trust.

Meltzer, R. (1975). Explorations in Autism: A Psychoanalytical Study. Karnac Books.

Meltzer, R. (1967). The Psycho-analytical Process. The Clunie Press.

Ogden, T. H. (1994). Subjects of Analysis. Karnac Books.

Ovídio (2007). Metamorfoses. Cotovia.

Pontalis, J-B. (1978). Entre le rêve et la douleur. Gallimard.

Resnik, S. (1994). Espace mental sept leçons à l'université. Éditions Érès.

Resnik, S. (1991). Espacio mental. Julián Yébenes Editores. 
Stern, D. (1986). The Interpersonal World of the Infant. Basic.

Tustin, F. (1981). Autistic States in Children. Routledge.

Tustin, F. (1973). Autistic Barriers in Neurotic Pa- tients. Karnac Books.

Winnicott, D. W. (1974). Fear of Breakdown. International Review of Psycho-Analysis, 1, 103107.

\title{
From Chaos To The Rebirth Of Psychic Space
}

\begin{abstract}
The author makes a psychoanalytical elaboration based on a clinical investigation in the case of a child, where she highlights the different psychic consequences that occurred as a result of early separations and losses. It shows how the psychic collapse arising after the absence of the maternal object causes a narcissistic encapsulation which is difficult to access and that functions as a barrier that nullifies or avoids close relationships. It highlights and elaborates the different movements of the analytical process that go from chaos, to the construction of a sound cointainer that involves the analytical duo, to the birth of the first words that served to represent primary depression.
\end{abstract}

Keywords

Psychic chaos, Psychic space, Primary depression, Psychic transformations. 